\title{
EL ACUERDO DE FACILIDAD AMPLIADA Y LOS DESEQUILIBRIOS DE LA ECONOMÍA PERUANA
}

\author{
Dra. BEATRIZ HERRERA GARCÍA
}

\section{A'NTECEDENTES}

Para el período 1999-2001, se espera que la economía peruana sea regida por la política económica delineada en el Tercer Acuerdo de Facilidad Ampliada, firmado entre el gobiemo y el FMI (Fondo Monetario Internacional).

El Acuerdo en sí trata de una especie de plan económico de mediano plazo cuya tendencia busca mantener la esencia de los dos Acuerdos de Facilidad Ampliada anteriores, aplicados desde 1993. La importancia del Tercer Acuerdo reside en ser un marco de referencia para los negocios y para los agentes económicos durante los próximos tres años.

Para el gobierno peruano significa el compromiso de continuidad en la política macroeconómica ortodoxa y el compromiso de establecer los linderos del accionar de la economía a través de las metas fiscales, la inflación, el crecimiento del producto bruto interno, la brecha externa y las reformas estructurales (privatizaciones, concesiones y gasto fiscal).

Hasta el año 2001 el gobierno peruano proyecta una recuperación de la tasa de crecimiento del PBI (producto bruto interno). Así en los Indicadores Macroeconómicos del Memorándum de Políticas Económicas y Financieras se preven metas de crecimiento del PBI estimadas en 3.0; 5.5 y 6.0 por ciento para los años 1999, 2000 y 2001, respectivamente.
En materia de inflación los pronósticos son de una tasa decreciente estimándose cerrar el período 1999-2001 con un nivel comparable al de los países altamente industrializados (3.0\%). Ello aseguraría, a manera de cobertura o "paraguas", la estabilidad económica a partir de la estabilidad de los precios.

Por el lado financiero, se reafirma el cumplimiento de las obligaciones financieras externas mediante la obtención de un superávit primario; es decir, se busca un resultado positivo en el presupuesto fiscal antes de pagar los servicios de la deuda externa. El superávit estimado sería de 0.9 por ciento del PBI en 1999, de 1.3 por ciento del PBI en el 2000 y de 1.6 por ciento del PBI en el 2001. El superávit primario estimado para este año le permitirá al gobierno peruano un leve déficit consolidado del presupuesto que compense la caída de la recaudación tributaria. La presión tributaria fue del 13.8 por ciento del PBI en 1998 y para 1999 se prevé una leve caída a 13.6 por ciento del PBI. Sin embargo, la presión tributaria se recuperaría con creces en los años 2000 y 2001, y llegaría al 14.0 y 14.2 por ciento del $P B I$, respectivamente.

\section{LA TRAYECTORIA DE LA DEPENDENCIA}

Durante el período 1990-1998 la economía peruana realizó progresos en materia de estabilización económica con políticas de ajuste de corte liberal 
(ortodoxo), luego de un largo período de crisis económica provocado, fundamentalmente, por los efectos de los servicios de la deuda externa durante la década de los ochenta.

Las políticas aplicadas en la década de los noventa han sido influenciadas, en primer lugar, por la trayectoria de la dependencia de la crisis de los ochentay, en segundo lugar, por la proyección de las economías centrales y el efecto de la globalización.

Los años ochenta serán recordados como la década perdida para el desarrollo económico, porque fueron años de crisis económica y financiera que pusieron en riesgo al Estado y redujeron sensiblemente los grados de libertad para la aplicación de políticas económicas contrarias a la ortodoxia vigente.

Con un entorno financiero externo desfavorable, con un proceso agudo de descapitalización interna, con un Estado sobredimensionado, empresas públicas ineficientes y con grandes déficits acumulados, y políticas económicas desarrollistas, el panorama económico era sombrío. La dimensión de la crisis se medía a través de la inflación que poco a poco fue tornándose en una hiperinflación; es decir, fuera del control de las políticas gubernamentales y con un efecto distorsionante en la organización del aparato productivo nacional (las organizaciones se tornaron en eminentemente especulativas). Lo acontecido en la década de los ochenta fue decisivo para justificar el cambio, así como para darle rumbo a la nueva trayectoria. Además, las relaciones económicas y financieras internacionales se habían globalizado en un contexto, también, liberal.

\section{ELADVENIMIENTO DE LA ESTABILIDADECONÓMICA}

Para superar la crisis heredada era inevitable restablecer la viabilidad externa, el crecimiento económico y el control de la inflación mediante políticas de ajuste de corte ortodoxo, debido a los resultados de los experimentos neoliberales en América Latina. La aplicación de ese tipo de políticas ofrecían logros en el control de los problemas fundamentales. Yaque los grados de libertad para la aplicación de políticas expansivas se había reducido sensiblemente.

La crisis económica debía ser enfrentada con firmeza. El primer gran obstáculo, la hiperinflación, debía ser controlada para facilitar la gobernabilidad del país. Como era un problema integral, fue necesario desarrollar una estrategia económica ortodoxa que comprometiera a la política monetaria, la físcal y la de comercio exterior. El punto de partida fue una política de ajuste con un gran "shock" de precios.

La política monetaria revirtió, radicalmente, su tendencia expansiva a una política monetaria restrictiva, de estricto control de la oferta monetaria y de la emisión primaria, esta última se ancló en el nivel de las RIN. El efecto inmediato fue la volatilidad de las tasas de interés, el retorno de las tendencias ahorristas y la especulación sobre el tipo de cambio, por lo que se optó que ambos precios relativos de la economía se sujetaran a las fuerzas del mercado. La flotación del tipo de cambio se mantuvo mediante la intervención del Banco Central que aseguraba mediante la "flotación sucia" el mantenimiento de una relativa banda cambiaria con un piso minimo.

Los dos precios relativos de la economía, tasa de interés y tipo de cambio, fueron claves en el control y manejo de la 
hiperinflación. La volatilidad de la tasa de interés y el control de la devaluación fueron medidas monetarias eficaces para revertir la tendencia de los precios de los bienes y los servicios, porque influyeron decisivamente en la menor demanda agregada y, por tanto, en los efectos recesivos de la economía.

La política fiscal, luego de haber normalizado las relaciones con los acreedores externos y haber reestructurado la deuda externa, logró el retomo a la viabilidad externa. A inicios de 1997 se concluyó una operación de reducción de deuda y servicios de deuda con los acreedores comerciales.

Para los próximos años el gobierno continuará orientando la política fiscal a los esfuerzos de reducir la inflación, a pesar de los grandes obstáculos surgidos durante 1998, debido principalmente al debilitamiento de la economía y a la contracción de la liquidez causada por la crisis registrada en los mercados financieros internacionales.

El crecimiento del PBI real se desaceleró a 0.7 por ciento en 1998 , al igual que las importaciones por lo que la producción, la oferta y la demanda global disminuyeron significativamente en relación al año precedente.

\section{EL PRODUCTO, LA OFERTA Y LA DEMANDA AGREGADAS}

La evolución del crecimiento del PBI refleja una desaceleración respecto a la tasa de crecimiento de 7.2 por ciento lograda durante 1997. El lento crecimiento de las exportaciones y de la inversión durante 1998 fueron consecuencia de los efectos de la crisis financiera internacional y del gran impacto de los efectos del fenómeno de $\mathrm{El}$ Niño, situación que retardó la ejecución de las reformas estructurales tendientes a modernizar el aparato productivo.

Como consecuencia de la caída del PBI la oferta global de bienes y servicios cayó al mismo nivel del producto. Por otro lado, es importante precisar la disminución de las importaciones de 8552 millones de dólares en 1997 a 8200 millones de dólares en 1998 (Al comparar los resultados del primer trimestre se indica 2073 millones de dólares para 1998 y 1538 millones de dólares para 1999).

\section{1}

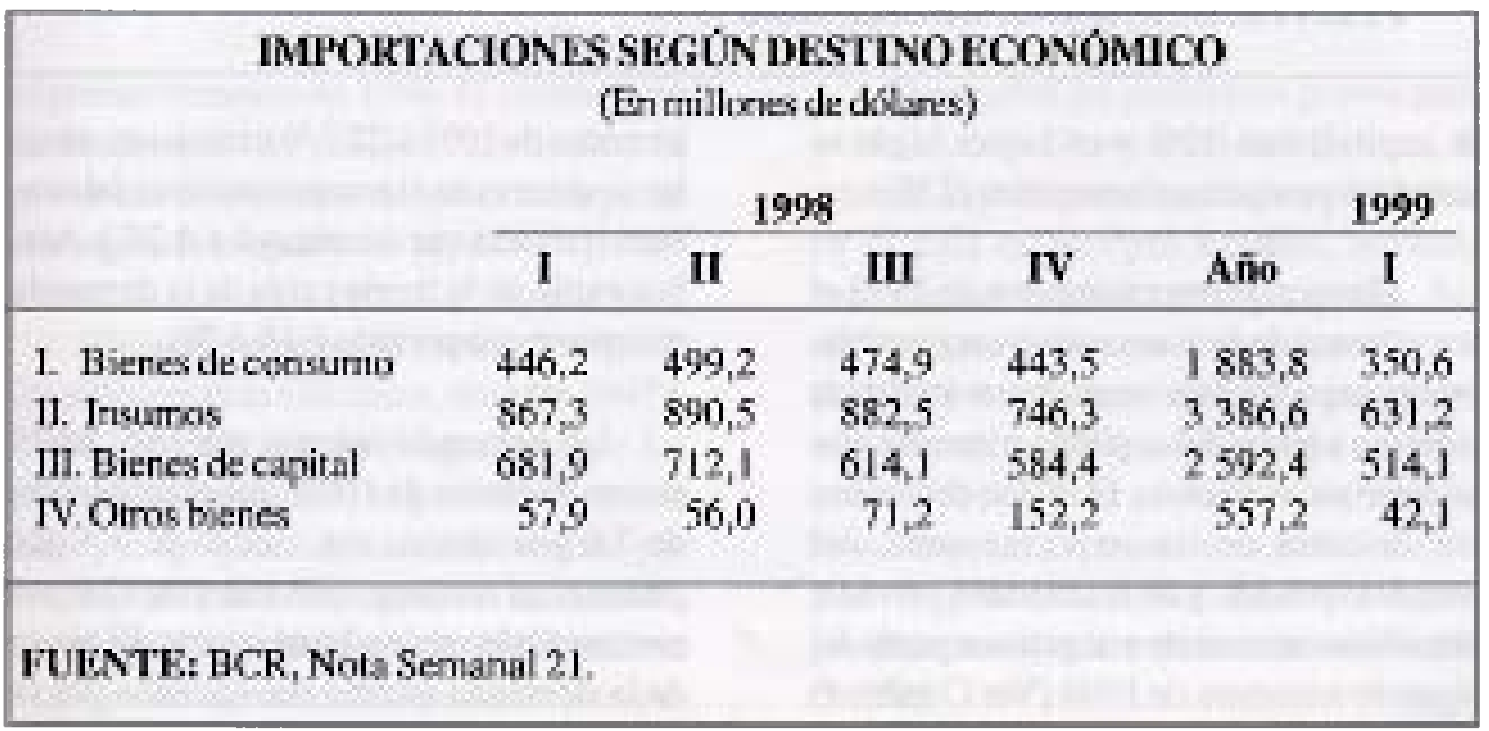


La estructura de las importaciones en términos porcentuales son los mismos para el año 1998 y para el primer trimestre de 1999. Así el rubro más importante resulta los insumos ( $41 \%$ ), seguido de la adquisición de maquinarias y equipos del exterior (bienes para alcanzar un pico de -17.8 por ciento en el cuarto trimestre del mismo año. La inversión privada que había crecido 13.5 por ciento en 1997 cayó al año siguiente en -0.4 por ciento; presentando, por otro lado, la más alta caída de la década en el primer

TABLA 4.2

\begin{tabular}{|c|c|c|c|c|c|c|c|}
\hline \multicolumn{8}{|c|}{$\begin{array}{l}\text { OFERTA Y DEMANDA GLOBAL } \\
\text { (Variaciones porcentuales reales) }\end{array}$} \\
\hline & \multicolumn{2}{|l|}{1997} & \multicolumn{2}{|c|}{1998} & \multirow[b]{2}{*}{ IV } & \multirow{2}{*}{\multicolumn{2}{|c|}{$\begin{array}{l}1999 \\
\text { Año } \quad \text { I }\end{array}$}} \\
\hline & Año & I & II & III & & & \\
\hline I. Oferta Global & 8.0 & 4.6 & -0.9 & 1.3 & -1.8 & 0.7 & -3.9 \\
\hline 1. PBI & 7.2 & 2.7 & -2.5 & 3.1 & -0.1 & 0.7 & 1.0 \\
\hline 2. Importaciones & 11.3 & 11.9 & 5.6 & -4.8 & -8.0 & 0.7 & -21.1 \\
\hline II.Demanda Global & 8.0 & 4.6 & -0.9 & 1.3 & -1.9 & 0.7 & -3.9 \\
\hline 1. Demanda interna & 6.7 & 7.9 & 0.1 & -0.8 & -7.0 & -0.2 & -10.6 \\
\hline a. Consumo privado & 4.0 & 2.6 & 0.5 & -0.4 & -3.4 & -0.3 & -4.2 \\
\hline b. Consumo público & 4.6 & 4.4 & -2.3 & 0.4 & 1.7 & 1.2 & 1.4 \\
\hline c .Inversión bruta int. & 12.7 & 19.6 & -0.1 & -1.8 & -17.0 & -0.3 & -23.8 \\
\hline i. Privada & 13.5 & 20.7 & -1.0 & -2.8 & -17.8 & 0.4 & -27.7 \\
\hline ii. Pública & 8.0 & 11.3 & 7.7 & 4.6 & -13.8 & 0.1 & 8.3 \\
\hline 2. Exportaciones & 13.0 & -5.8 & -4.8 & 9.3 & 17.7 & 3.8 & 20.2 \\
\hline
\end{tabular}

de capital) con $32 \%$ y en tercer lugar se sitúan los productos alimenticios (23\%).

Hasta el primer trimestre de 1998 el crecimiento de la economía era sostenible, sin embargo, se observa una fuerte tendencia recesiva a partir del segundo trimestre con características de crisis. El PBI se desacelera por la caída de las importaciones, del consumo privado y de la inversión privada; esta última se revierte a negativa a partir del segundo trimestre de 1998 (Ver Cuadro 1) trimestre de $1999(-27.7 \%)$, situación similar se observa en el comportamiento del consumo privado que disminuyó (-4.2\%). Ambos explican la fuerte caída de la demanda interna en ese período $(-10.6 \%)$.

La demanda interna registró, en el cuarto trimestre de 1998, una disminución de 7.0 por ciento, con caídas de 3.4 por ciento en el consumo privado y de 17.0 por ciento en la inversión bruta interna. El ajuste de la demanda interna fue causado por la 
retracción del flujo de financiamiento externo de corto plazo en 987 millones de dólares (Ver Cuadro 4.2).

El debilitamiento del producto bruto interno se puede analizar al comparar la evolución sectorial dentro del producto bruto interno en los años 1997 y 1998 y durante ración. De mantenerse la tendencia en el año, el "cinturón" de seguridad alimentaria no presentaría problemas y aliviaría la presión importadora de alimentos por el lado de los productos agropecuarios, mientras que la recuperación de la pesca significará la normalización de los flujos de caja en moneda extranjera.

TABLA 4.3

\begin{tabular}{|c|c|c|c|c|c|c|c|}
\hline \multirow[b]{3}{*}{ SECTOR } & \multicolumn{7}{|c|}{$\begin{array}{l}\text { PRODUCTO BRUTO INTERNO } \\
\text { (Variaciones porcentuales reales) }\end{array}$} \\
\hline & 1997 & & & 1998 & \multicolumn{3}{|c|}{1999} \\
\hline & Año & I & II & III & IV & Ã̃o & I \\
\hline Agropecuario & 4.9 & 4.5 & -2.1 & 2.1 & 15.4 & 3.6 & 10.3 \\
\hline Pesca & -12.2 & -63.5 & -64.2 & 0.6 & 52.3 & -35.7 & 113.2 \\
\hline Minería & 5.8 & 3.5 & -1.4 & 7.1 & 9.8 & 4.8 & 13.5 \\
\hline Manufactura & 6.6 & 1.2 & -10.3 & 2.0 & -4.1 & -3.0 & 2.3 \\
\hline Construcción & 18.9 & 8.6 & 7.5 & 7.7 & -11.2 & 2.3 & -12.8 \\
\hline Comercio & 7.3 & 2.2 & -1.2 & -0.2 & -5.9 & -1.3 & -7.4 \\
\hline Otros servicios & 6.3 & 3.2 & 2.2 & 2.8 & 0.2 & 2.1 & -0.3 \\
\hline PBI & 7.2 & 2.7 & -2.5 & 3.1 & -0.1 & 0.7 & 1.0 \\
\hline
\end{tabular}

el primer trimestre de 1999. El contraste en la tendencia del crecimiento indica la presencia de un punto de inflexión a partir del segundo trimestre de 1998.

Debido a efectos de carácter exógeno los sectores más afectados, durante 1997 y 1998 , fueron la pesca y el agropecuario. La pesca tuvo resultados negativos en ambos años y el agropecuario creció levemente por encima de la tasa demográfica. En cambio, en el primer trimestre de 1999 ambos sectores muestran una expectante recupe-
Superados los problemas provocados por la burbuja financiera internacional, la minería, cuyo impactoen el ingreso de divisas en el país es siempre notable, también muestra un considerable progreso. Sin embargo, no todo es positivo en la evolución del PBI, y en contraste a los años anteriores, sectores de notable rendimiento como la construcción y el comercio han caído sensiblemente. De mantenerse esta situación podría provocarse un efecto contraproducente en la tasa de crecimiento anual del PBI. 
El sector más importante de la economía nacional, el manufacturero, se encuentra lejos de brindar los resultados de 1997 y es posible que esta tendencia sea mantenida por los niveles negativos de la inversión privada, la cual se redujo en -27.7 por ciento en el primer trimestre de 1999.

El ahorro público continuará jugando un papel central en la reducción de la brecha interna o fiscal, por lo que se espera una elevación del ahorro público para dejar mayor espacio a la inversión privada que se ha retraído fuertemente.

Durante 1998, el resultado primario del SPNF (Sector Público No Financiero) equivalió a 1.2 por ciento del $\mathrm{PBI}$, inferior al de 1997 (1.7 \% del PBI), debido a una disminución de los ingresos corrientes del gobierno central de 14.1 a 13.8 por ciento del PBI y a una reducción del resultado primario de las empresas públicas de 0.7 a 0.1 por ciento del PBI, todo lo cual fue compensado por una disminución de los gastos financieros del gobierno central de 13.4 a 13.2 por ciento del PBI. En $1998 \mathrm{el}$ resultado económico fue negativo en 0.6 puntos porcentuales del PBI, contrastando con el resultado del año 1997 (0.0\%).

Durante el primer trimestre de $1999 \mathrm{el}$ resultado económico del sector público fue deficitario en el equivalente a 0.7 por ciento del PBI. Este resultado, que contrasta con el superávit de 1.0 por ciento obtenido en el primer trimestre de 1998, se explica por la disminución de los ingresos corrientes del gobierno central de 15.4 a 14.5 por ciento del PBI y por el incremento de los gastos no financieros como de los gastos financieros para el pago de la deuda (de 1.5 a $2.0 \%$ del PBI).

\section{ELDESEQUILIBRIO FUNDAMENTAL DELA ECONOMÍA}

Una de las constantes de los últimos años ha sido y es el déficit en cuenta corriente de la balanza de pagos, que mide la magnitud de la brecha externa de cada país.

A pesar de los grandes esfuerzos realizados, la situación es delicada a tal punto que puede ser definida como el "Talón de Aquiles" de la economia, porque es un indicador de la vulnerabilidad de las economías domésticas en un mundo globalizado. Eso quiere decir que los efectos de las crisis financieras internacionales tienen un impacto desproporcionado por la existencia de tales brechas.

También ha sido una constante de la década el mayor flujo de capitales extranjeros que ha permitido financiar los crecientes déficit externos y revaluar las monedas domésticas. Sin embargo, ésta no es la única fuente de financiamiento de tales déficits porque existen para esos efectos los ingresos por privatización de las empresas estatales, los flujos de inversión extranjera de largo plazo, los préstamos de los organismos financieros internacionales y las reservas netas.

La cuenta corriente es la parte más importante de una balanza de pagos internacionales, además, indica la posición del país en relación al resto del mundo y refleja, por tanto, la capacidad competitiva internacional. Como se ha mencionado el déficit en cuenta corriente ha sido una constante y se produce al ocurrir un desbalance financiero en condiciones de ausencia de un sector exportador vigoroso. Si bien el modelo económico liberal apuesta por una economía cada vez más integrada al mundo gracias al éxito de las políticas exportadoras, la realidad indica que esos resultados sólo podrán alcanzarse en el largo 
plazo y dependerá mucho de la fortaleza de las economías centro.

En el período de reestructuración económica, la economía peruana no ha logrado despegar porque el sector exportador no ha crecido a las tasas esperadas, sino al contrario ha mostrado tendencias contraproducentes. En este contexto, una "huida" de capitales provocada por las burbujas financieras creaba problemas por el lado del sector externo manifestándose en déficit crecientes de la balanza de pagos en cuenta corriente.

El déficit en cuenta corriente de la balanza de pagos venía mostrando a lo largo de los años una tendencia oscilante hasta la

TABLA 5.1

LA CLEVI'A COAHERLE 1950-1998

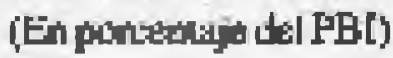

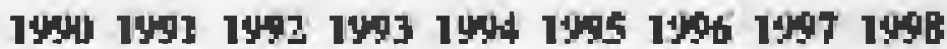

Détialen Quent:

Cortitonte det to

Batanza de Pugos $\begin{array}{lllllllll}3.5 & 3.6 & 5.6 & 5.6 & 5.3 & 7.3 & 5.9 & 5.2 & 60\end{array}$

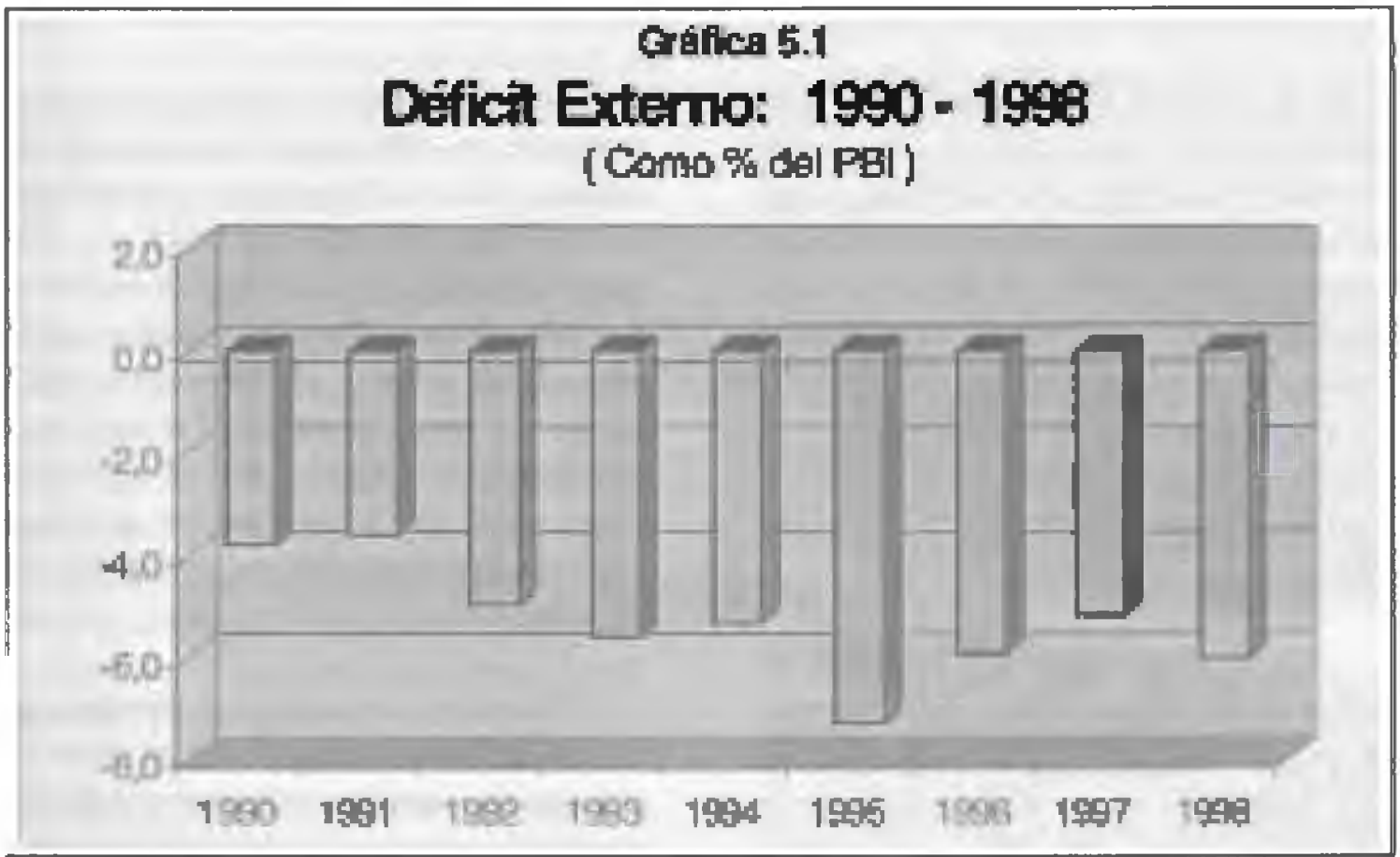


TABLA 5.2

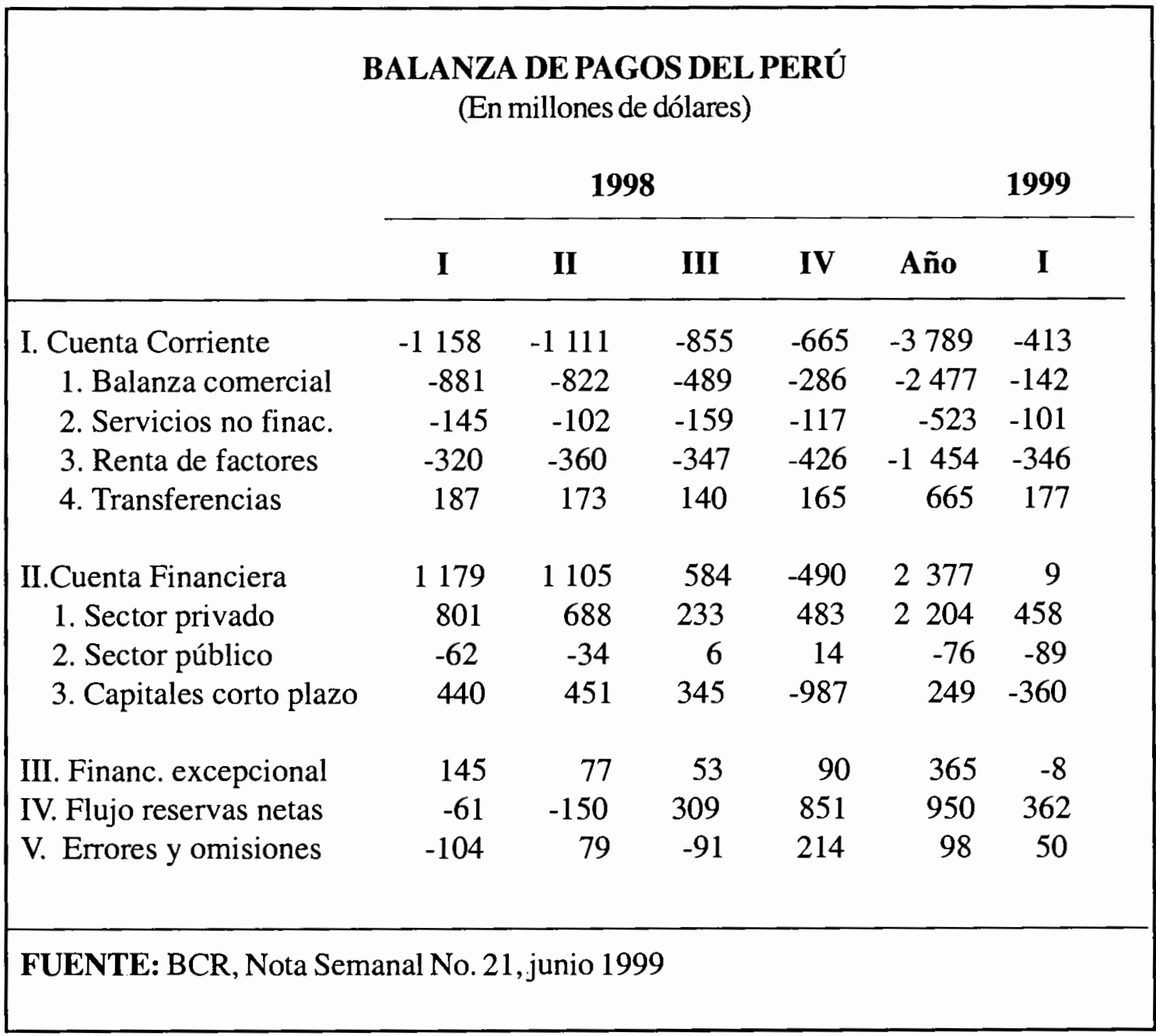

primera mitad de 1998 , cuando aumentó debido a una contracción en las exportaciones; sin embargo, en la segunda mitad del año, el estancamiento de las importaciones terminó contribuyendo al cierre de la brecha externa. Al final el año cerró con un indicador más alto de déficit (6.0\% del PBI). En esa tendencia, para 1999 se estima una recuperación de las exportaciones pesqueras y un déficit esperado de 5.5 por ciento del PBI.

En el primer trimestre de 1999 , el déficit en la cuenta corriente de la balanza de pagos fue de 413 millones de dólares (3.3\% del PBI) menor al de igual período en 1998 ( $7.8 \%$ del PBI). La cuenta financiera fue positiva en 1998 y en el primer trimestre de 1999 llegó a 9 millones de dólares, inferior al flujo del primer trimestre de 1998 en 1170 millones de dólares. En particular destaca el menor flujo de capitales privados de corto plazo ascendente a 249 millones de dólares, muy por debajo del monto registrado en 1997 (2 318 millones de dólares). Sin embargo, durante el primer trimestre de 1999, los capitales de largo plazo financiaron la totalidad del déficit en cuenta corriente.

Por la importancia y los efectos que tiene el déficit en cuenta corriente sobre la economía peruana es que denomino al déficit en cuenta corriente de la balanza de pagos 
como el "Talón de Aquiles" de nuestra economía. La razón es que, el déficit en cuenta corriente peruano, que tanto preocupa a los inversionistas extranjeros, mostraría una leve disminución en 1999 debido principalmente a la fuerte caída experimentada en los últimos meses en las importaciones de bienes y servicios.

En 1999, el Perú requerirá financiar unos 3400 millones de dólares para cubrir el déficit de 1998. Como se recuerda, gran parte de ese déficit fue financiado de manera tradicional con inversiones extranjeras directas, ingresos por privatización y créditos privados.

\section{LAS POLÍTICAS AL FINALIZAR EL MILENIO}

Durante 1999 existirán fuerzas contrapuestas sobre la actividad económica. De un lado, las presiones expansivas provendrán, tanto de la recuperación de los sectores primarios ante la normalización de las condiciones climáticas, como de un esperado fuerte impulso fiscal. Sin embargo, ante una mayor escasez del financiamiento externo de corto plazo, el crecimiento económico se vería atenuado por un menor incremento del crédito, mayores tasas de interés y un mayor tipo de cambio real.

Por lo tanto, en el mediano plazo, deberá asegurarse la elevación del ahorro interno como fuente estratégica del financiamiento de la inversión bruta interna. En ese sentido, se espera que la inversión doméstica y el ahorro nacional sean fortalecidos mediante la continuación de las reformas económicas, buscando cada vez una mayor participación del sector privado nacional y extranjero.

En el Acuerdo, entre el gobierno y el Fondo, se contempla un incremento de la inversión bruta interna de 22.9 por ciento del PBI en 1999 a 23.8 por ciento del PBI en 2001, es decir, se proyecta una mejora de la inversión total en el mediano plazo de aproximadamente un punto porcentual. Este incremento correspondería, exclusivamente, al mayor esfuerzo del sector privado en los sectores estratégicos de telecomunicaciones, energía, minería y construcción.

Por el lado del ahorro nacional se proyecta un aumento del ahorro doméstico, de un nivel bajo como el 17.8 por ciento del PBI en 1999 hasta el 19.0 por ciento del PBI en 2001. Del incremento de 1.8 puntos porcetuales recaería el mayor esfuerzo en el ahorro público (casi el $50 \%$ ). De lograrse este objetivo el ahorro externo se reduciría de 6.0 por ciento del PBI en 1998 (es igual a la brecha o déficit externo, ver gráfica 5.1) a 5.1 por ciento del PBI en 1999.

En el mediano plazo, la política económica buscará el aumento del ahorro doméstico, lo que permitirá que los inversionistas privados puedan tener un mayor campo de acción. En ello resulta clave el cumplimiento de los objetivos referentes al superávit primario (en el que no se incluyen los ingresos por privatización) del sector público consolidado. La meta es alcanzar un superávit primario del 1.6 por ciento del PBI en 2001.

Entre los objetivos y metas contenidas en el Acuerdo y la coyuntura económica nacional hay una evidente disparidad, que hace vaticinar a 1999 como un año especialmente difícil porque de los resultados que se obtengan en el corto plazo dependerán que se logren las metas acordadas con el Fondo.

En el corto plazo los efectos de la demanda interna son contraproducentes con la estabilidad macroeconómica. En efecto, la demanda interna (gasto agregado) sigue decreciendo durante el primer trimestre de 
1999. Esta tendencia se viene observando desde el tercer trimestre de 1998 cuando la demanda interna cayó en -0.8 por ciento, luego en el cuarto trimestre del mismo año volvió a caer a -7.0 por ciento y en el primer trimestre de 1999 tuvo su caída más alta en lo que va de la década llegando a -10.6 por ciento. Como se afirmó líneas arriba este comportamiento reflejaba la fuerte retracción de la inversión privada durante casi un año (en el primer trimestre de 1999, la inversión privada decreció hasta -27.7 por ciento). Estos resultados son indicios de los efectos de la coyuntura sobre el crecimiento de largo plazo.

Debido a la tendencia decreciente de la demanda interna, que resulta por otro lado de la disparidad dinámica de sus componentes: exportaciones crecientes e inversión decreciente, es poco probable que se reduzcan las tasas de desempleo y la pobreza crítica debido a que los sectores económicos mayormente afectados son los denominados estratégicos para el crecimiento y el empleo, como son los sectores manufacturero, comercio, servicios y construcción.

El manejo fino de la política económica y un mayor flujo de recursos externos deben complementarse con una apropiada política fiscal y un seguimiento estricto de las variables monetarias, las cuales deben conjugarse con las mejoras en las expectativas de los agentes económicos, en la cual podría jugar un papel fundamental la explotación del gas de Camisea, y de la tendencia y comportamiento de los dos precios relativos claves de la economía. 